Lujin Pan, Sebastian Ott, Fabio Dionigi, Peter Strasser

Current challenges related to the deployment of shape-controlled Pt alloy oxygen reduction reaction nanocatalysts into low Pt-loaded cathode layers of proton exchange membrane fuel cells

Journal article | Accepted manuscript (Postprint)

This version is available at https://doi.org/10.14279/depositonce-10639

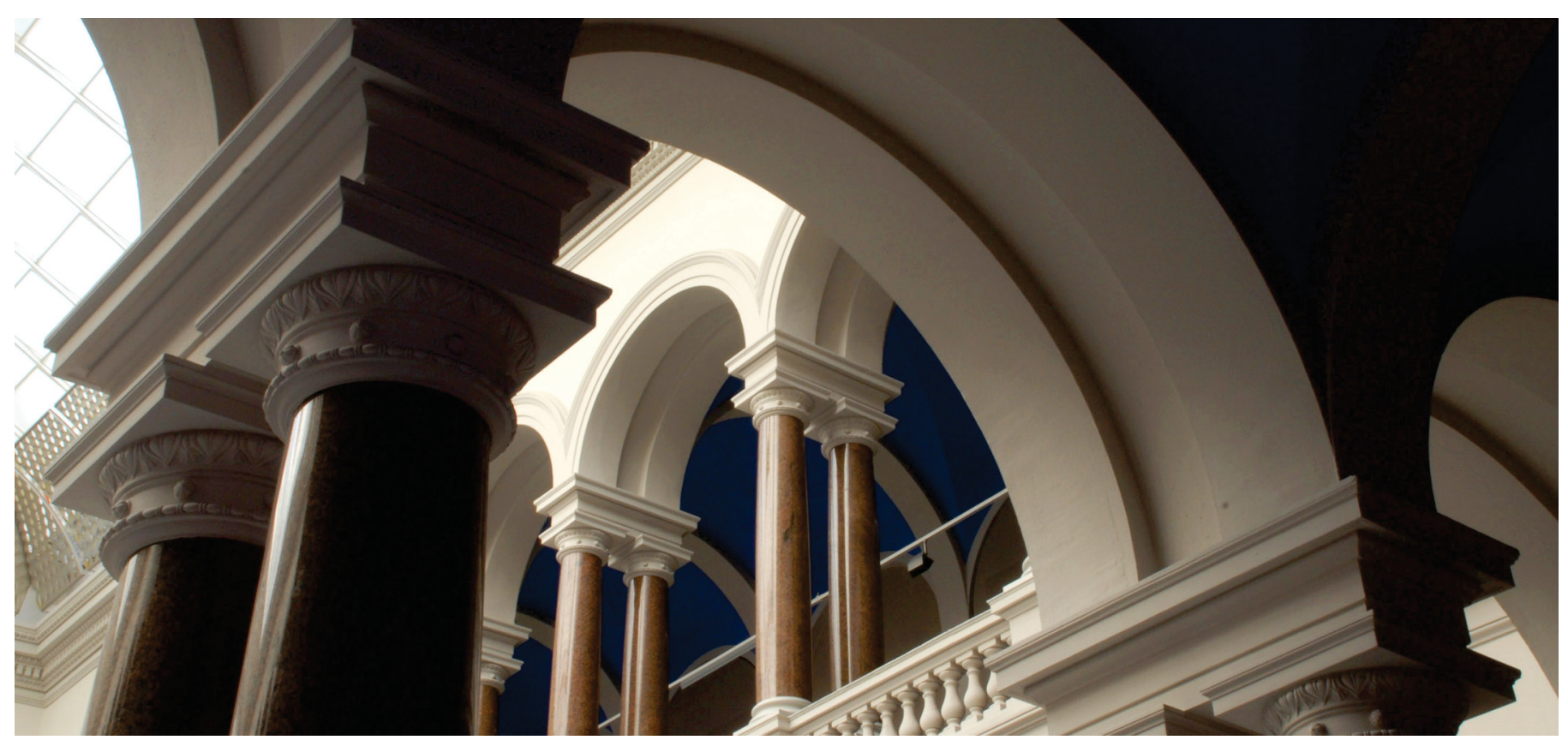

Pan, L., Ott, S., Dionigi, F., \& Strasser, P. (2019). Current challenges related to the deployment of shapecontrolled Pt alloy oxygen reduction reaction nanocatalysts into low Pt-loaded cathode layers of proton exchange membrane fuel cells. Current Opinion in Electrochemistry, 18, 61-71.

https://doi.org/10.1016/j.coelec.2019.10.011 


\title{
Current challenges related to the deployment of shape-controlled Pt alloy oxygen reduction reaction nanocatalysts into low Pt-loaded cathode layers of proton exchange membrane fuel cells
}

\author{
Lujin Pan, Sebastian Ott, Fabio Dionigi and Peter Strasser*
}

\begin{abstract}
The reduction of the amount of platinum used in proton exchange membrane fuel cell cathodes at constant power density helps lower the cell stack cost of fuel cell electric vehicles. Recent screening studies using the thin film rotating disk electrode technique have identified an ever-growing number of Pt-based nanocatalysts with oxygen reduction reaction Ptmass activities that allow for a substantial projected decrease in the geometric platinum loading at the cathode layer. However, the step from a rotating disk electrode test to a membrane electrode assembly test has proved a formidable task. The deployment of advanced, often shape-controlled dealloyed Pt alloy nanocatalysts in actual cathode layers of proton exchange membrane fuel cells has remained extremely challenging with respect to their actual catalytic activity under hydrogen/oxygen flow, their hydrogen/air performance at high current densities, and their morphological stability under prolonged fuel cell operations. In this review, we discuss some of these challenges, yet also propose possible solutions to understand the challenges and to eventually unfold the full potential of advanced Pt-based alloy oxygen reduction reaction catalysts in fuel cell electrode layers.
\end{abstract}

\section{Addresses}

The Electrochemical Energy, Catalysis and Materials Science Laboratory, Department of Chemistry, Chemical Engineering Division, Technical University Berlin, Berlin, Germany

*Corresponding author: Strasser, Peter (pstrasser@tu-berlin.de)

\section{Keywords}

Fuel cells, Catalysis, Pt alloys, MEA, Mass transport, Scale up.

(C) 2019. This manuscript version is made available under the CC-BY-NC-ND 4.0 license http://creativecommons.org/licenses/by-nc-nd/4.0/ 


\section{Introduction}

A hydrogen-based Proton Exchange Membrane fuel cell (PEMFC) is a device that converts chemical energy of hydrogen and oxygen into electricity. It is promising because of its high theoretical efficiency and zero carbon emission. However, the commercialization of PEMFCs, most notably in the automotive field, has started yet has remained limited by high cost as well as performance and durability challenges. Among these, challenges related to the PEMFC cathode, where the electrochemical oxygen reduction reaction (ORR) occurs, continue to require the most attention. Cuboctahedral or essentially spherical dealloyed Pt-based alloy catalysts are the most active cathode catalysts for the conversion of molecular oxygen to water. Recent years, however, have seen a stronger focus on the relation between morphological properties of nanoparticle Pt-based catalysts, such as shape [1,2] or size [3], and their catalytic ORR performance. This has led to the development of a number of new shape-controlled dealloyed Pt alloybased ORR catalyst concepts. Discovery and subsequent validation and further development of novel PEMFC catalysts is a very time consuming and costly process. First, new electrocatalysts are typically synthesized in very small quantities at the lab scale, say on the order of hundreds of milligrams. Typically, these catalysts, cast into extremely thin layers, are screened in half-cell configurations for catalytic ORR activity under ideal film electrode conditions. While not all researchers in the field share this view, rapid activity screenings of new and largely unexplored catalysts for the purpose of rapid down selection and exclusion of inactive materials remains a reasonable path forward before scale-up fuel cell testing. The most popular half-cell screening techniques include the thin-film rotating disk electrode (RDE), but there are alternative techniques on the way to single fuel cell testing available today, in particular the floating electrode techniques (FETs) and the half-cell gas diffusion electrode (GDE) configuration technique (Figure 1).

\section{The performance gap enigma between RDE and membrane electrode assembly}

The thin-film RDE technique is the most popular electrochemical activity screening technique, for instance used for decades for the screening of catalysts for the hydrogen oxidation reaction or ORR [4,5, 59-61]. This is partly because of the low-cost nature and facile accessibility of the required components of a RDE set up. The cost and availability of rotators and the standardized disks are low and acceptable. Also, the test protocols are well established [*6,7], and a well-trained operator can measure several electrochemical activities in a day. Moreover, RDE measurements exclude the influence of other membrane electrode assembly-related factors and components. RDE tests are rapidly capable to assess a surface-area specific activity (SA) value, a Pt-mass activity (MA) value, and, under certain conditions, an electrochemical surface area (ECSA) value of Pt-based catalysts. The caveat lies in the relatively small current densities and very small geometric catalyst mass loadings to keep the catalyst film sufficiently thin. Thus, although RDE is a versatile screening technique, the low solubility and the poor mass transfer of oxygen in $\mathrm{HClO}_{4}$ electrolytes only allow for performance data at very low limiting current densities.

For practical fuel cells, however, the limiting currents have to be at least three orders of magnitude larger than in RDE to achieve the required device performance targets. This why in practical fuel cells Membrane Electrode Assemblies (MEAs) combined with Gas Diffusion Layers are used, which result in much high local oxygen partial pressures at the active surface sites of the catalysts and thus much higher current densities compared with the RDE. This is why RDE tests are in principle unable to predict high power densities of fuel cell catalysts. What is more, however, researchers have realized that even the exceptional 
low-current power densities observed in RDE tests of advanced shape-controlled bimetallic Pt nanocatalysts (reported in Pt MAs at $0.9 \mathrm{~V}$ cell potential or potential versus RHE), which were designed for the purpose of lowering the fuel cell Pt utilization, could not be realized in electrode layers of single cell MEAs to date. To make matters worse, the carefully designed morphology of these catalysts, their surface facet structure, and surface compositions turned out hard to stabilize [8]. This is believed to be one major contribution to the stark discrepancy between the Pt mass activities of RDE tests and those of single MEA tests. This discrepancy and the narrow accessible current density range accessible in RDE experiments have triggered and driven the development of alternative screening techniques without the power density shortcomings of RDE experimentation.

\section{Bridging technologies between RDE and MEA}

To improve the mass transport and preserve the facile application of RDE, Zalitis et al. put forward a floating electrode technique for ultra-low loading Pt catalyst. They deposited the low loading catalysts directly onto a modified porous substrate; herein, the pores functioned as the $\mathrm{O}_{2}$ pathways and allowed for fast diffusion of the reactant. The substrate was made hydrophobic so that it could float on the liquid electrolyte. It also comprised a thin sputtered Au layer so that the deposited electrocatalyst thin film is electrically contacted as in a standard three-electrode setup [9]. Using the FET, large ORR current densities were obtained, because the ionomer or solution film was thin enough (nm scale) to enable excellent $\mathrm{O}_{2}$ mass transfer. This is why the limiting currents of the FET approached the MEA currents and ORR catalyst activities could now be evaluated at high current densities, as well. An alternative for bridging the gap between the RDE screening technique and single MEA/gas diffusion layer (GDL) testing consists of operating a catalyst coated GDL, resulting in a GDE, in a half cell configuration [10,11]. The GDE is thereby interfaced with a liquid electrolyte on one side and with a pressurized gas on the other. This set up constitutes a versatile electrochemical test reactor for new electrocatalysts for either galvanic or electrolytic cells. For fuel cell cathode developments, $\mathrm{O}_{2}$ is provided on one side of the GDE, while the other side either faces directly a liquid acid electrolyte or it is separated from it by a PEM membrane. Together, this is to mimic a MEA/GDL situation of a single fuel cell. Unlike the limited reactant mass transport in a RDE environment, the half-cell GDE ideally exhibits a comparable oxygen mass transport to the electrode as a fuel cell device, despite the much simplified construction. The half-cell GDE test technique has been largely applied and used with commercial Pt catalysts, while their application to dealloyed/alloy PtX or shapecontrolled advanced Pt alloy cathode electrocatalysts is only now emerging, yet appears extremely promising [12]. 


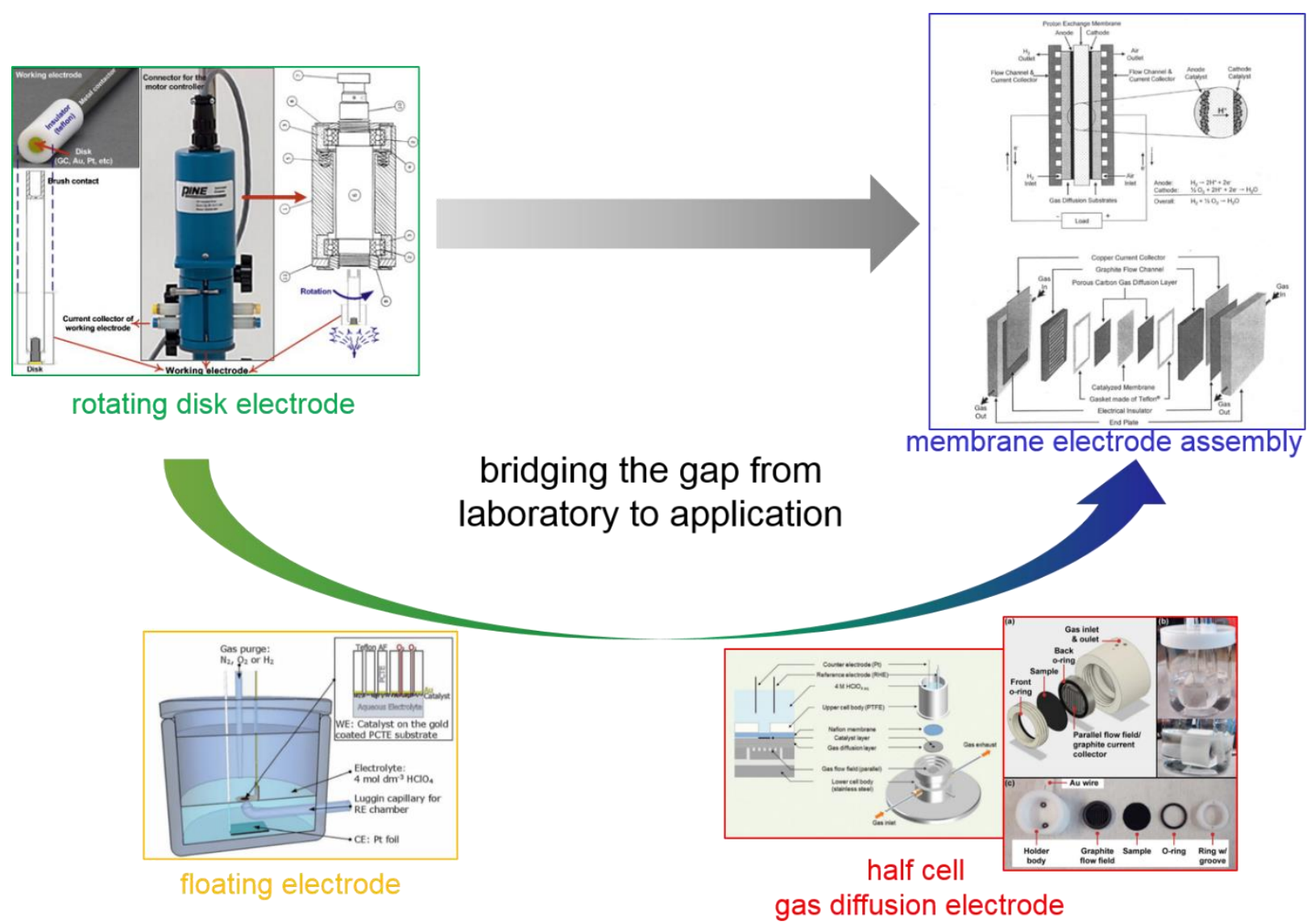

Figure 1. Bridging the performance gap from screening to device. Intermediate techniques discussed include the rotating disk electrode (upper left), the floating electrode technique (bottom left), the half-cell gas diffusion electrode technique (bottom right) and the single cell Membrane Electrode Assembly (MEA) (upper right). The setup figures are adopted from literatures by Guy Denuault et al. [13], Zalitis et al. [9], Inaba et al. [11], Pinaud et al. [10] and K.R. Cooper et al. [14].

In 2018, Martens et al. reevaluated a typical RDE measurement protocol using a supported Pt/C nanoparticle benchmark catalyst and directly compared and contrasted its activity and stability data obtained from RDE, FET, and MEA [*6]. The absolute MA at $0.9 \mathrm{~V}_{\mathrm{RHE}}$ of these three techniques compared quite reasonably considering the different operating temperatures. Hence, adhering to a strictly consistent measurement protocol, RDE data can produce reproducible cross-laboratory activity and stability results. RDE therefore remains a useful tool for preliminary screening of fuel cell catalysts.

Unlike RDE, the FET does not encounter serious mass transport limitations in the potential region from 0.6 to $0.8 \mathrm{~V}_{\mathrm{RHE}}$, which is more relevant for fuel cell power density predictions. Yet, while the oxygen mass transport is much enhanced, still only activity trends appeared to be comparable because of unequal operating conditions and catalyst layer structures. Then, half-cell GDE measurements under actual PEMFC operating conditions provided very similar results as single fuel cell MEA data [11]. Thus, such half-cell MEA measurements offer accurate trends in fuel cell catalyst activity. Still, where possible, early-stage single cell MEA screening remains desirable, because this represents the most relevant and real measurement environment. 


\section{ORR activity of advanced Pt alloy nanoparticles in MEA - low current density region}

In this section, we focus on the state-of-the-art ORR activities that have been actually reported to date for recently developed, highly promising since highly RDE-active Pt-based alloy catalyst concepts, when they were deployed as electrode layers at the cathode of single cell MEAs. To increase the absolute catalytic ORR Pt-MA, either the SA $\left(\mathrm{mA} / \mathrm{cm}^{2}\right)$ or/and the ECSA $\left(\mathrm{m}^{2} / \mathrm{g}_{\mathrm{Pt}}\right)$ value must be maximized or optimized. SA represents the overall intrinsic activity of the active sites controlled by electronic ligand and/or lattice strain effects [15]. Triggered by the structure sensitivity of PtNi bimetallic "skin" single crystal facets, over the past 12 years, tremendous efforts were put into a detailed control of the morphological shape and the type of the exposed facets of Pt alloy nanoparticle ORR catalysts, combined with careful engineering of the surface composition of the catalyst particles. By means of tuning the electronic structure and exposed facets, new advanced Pt alloy nanocatalysts were discovered and developed that showed impressive catalytic Pt mass based activities - however exclusively in thin film RDE tests. Octahedral PtNi alloy nanoparticles showed high MA in thin film RDE, but the maintenance of the nanoparticles shape remained challenging, partially because of the leaching of $\mathrm{Ni}$ atom during the electrochemical process $[1,2,16,17]$. To improve the catalyst stability, additional metals, such as Mo [18], Rh [19], and Ga [20] were added onto the surface of the octahedra, supposedly to maintain the favorably reactive (111) facets. Besides multimetallic Pt alloys, the reactivity of pure Pt-based catalysts can be tuned via the controlling of the intrinsic strain and the optimization of coordination numbers of the surface active sites [21,22]. For example, the enhanced ORR activity of the dealloyed jagged Pt nanowires by Li et al. was attributed to the undercoordinated surface atoms [23]. More recently, alloys of Pt and rare earth elements have attracted much interest as ORR catalysts in PEMFC [24]. Again, despite their promising catalytic performance in thin film RDE studies, measurements in PEMFC have remained at an early stage and have not resulted in comparable power densities [25,26]. In parallel to efforts to improve the MA, geometric arrangements have been applied to increase the ECSA, e.g. decrease dimensions of Pt nanoparticles, nanowires, nanotubes or nanocrystals core/shell nanostructure strategies using a non-noble core, recently mostly $\mathrm{Ni}$, with an ultrathin Pt shell [23,27-29]. The experimental MEA fuel cell performance of these type of advanced Pt alloy nanocatalysts has also remained low, possibly again because of the harsher reaction conditions under Single cell conditions, high operation currents and temperatures, combined with the larger number of potential sweep cycles. For example, Mauger et al. discussed some of these challenges for PtNi nanowires in MEA and showed that pre-leaching of $\mathrm{Ni}$ and low ionomer content maximized the MEA performance [30]. As depicted in Fig.2a, their MEA activity performance to date continues to lack far behind their RDE activity at the same electrode potential. The improvement factor with respect to a state-of-art Pt catalysts is less than $4 \mathrm{x}$ in a single cell MEA configuration, while in thin film RDE tests factors of 10x and higher were achieved. We note that in Fig.2, while the operating conditions are similar, cells and protocols varied a lot among these experiments. Hence comparison has to be taken with care, and it is meant as a gross semiquantitative comparison. Recently, some in situ characterization studies have elucidated the mechanism of catalysts degradation mechanism [31-33]. They provided some fundamental understanding of catalyst structure transformation or agglomeration motion during the cycling and guideline the nanoparticle manufactures for future industrial application. 

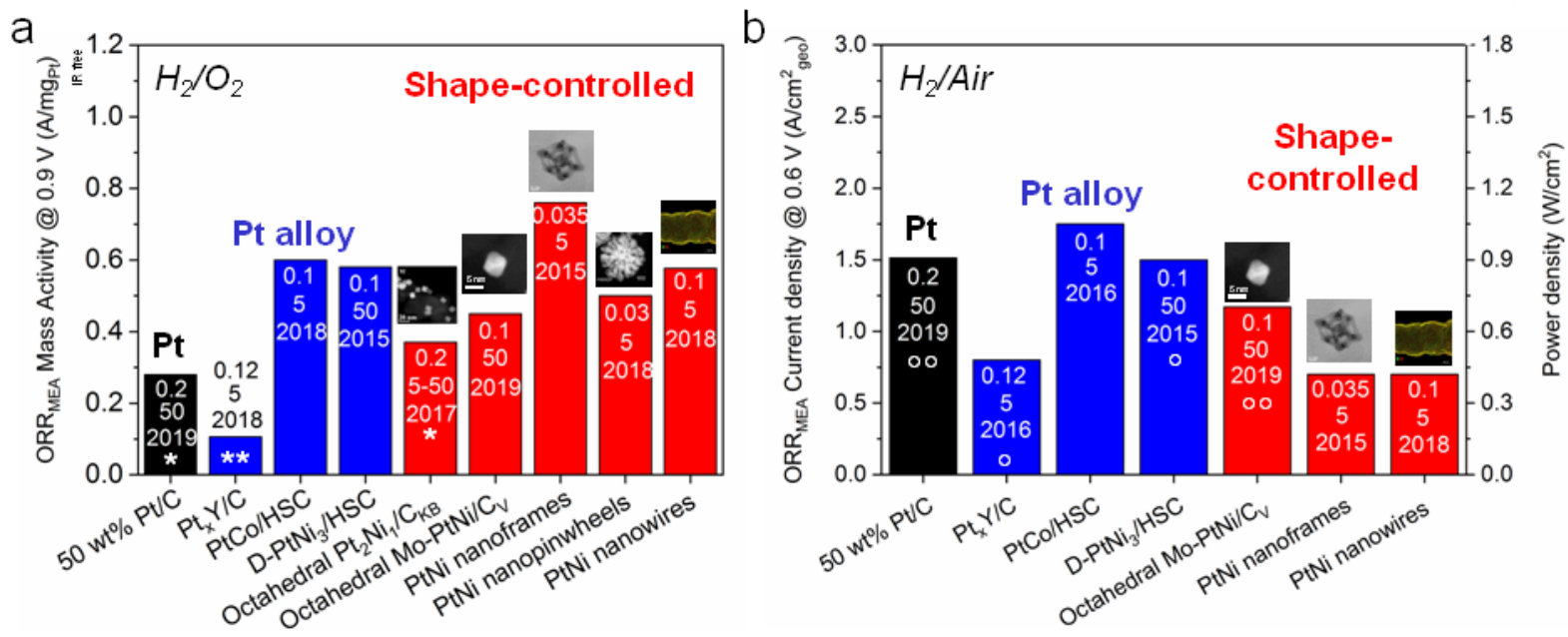

Figure 2. Comparison of today's published Pt mass-based ORR activities of some of the most RDE-active advanced Pt alloy nanocatalysts developed over the past decade. (a) ORR mass activities are measured at $0.9 \mathrm{~V}_{\text {Cell }}$ in single fuel cell MEAs under hydrogen/oxygen feeds. (b) Power densities are measured evaluating the ORR current densities at $0.6 \mathrm{~V}$ in single fuel cell MEAs under hydrogen/air feeds. Catalysts include from left to right: Carbon-supported Pt catalysts are used as benchmark and reference (black bar), dealloyed carbon-supported Pt alloys are shown in blue bars, and shape-controlled dealloyed Pt alloy nanocatalysts are shown in red bars: Pt/C [34], Pt $\mathrm{x}_{\mathrm{x}} \mathrm{C}$ [25], PtCo/HSC [35,36]**, dealloyed "D"$\mathrm{PtNi}_{3} / \mathrm{HSC}$ [37], octahedral $\mathrm{Pt}_{2} \mathrm{Ni}_{1} / \mathrm{C}_{\mathrm{KB}}$ [38]*, octahedral Mo-PtNi/C ${ }_{\mathrm{V}}$ [34], PtNi nanoframes [39], PtNi nanopinwheels [40], PtNi nanowires [41]. Notations: "D", dealloyed"; "HSC", high surface area carbon; " $\mathrm{C}_{\mathrm{KB}}$ ", Ketjen black carbon, and "C $\mathrm{C}_{\mathrm{V}}$ ", Vulcan carbon. Worth mentioning even though not included in the bar plot in (a) are Pt-Ni nanocages with a performance of $0.191 \mathrm{~A} \mathrm{mg}_{\mathrm{Pt}^{-1}}$ [42]. The numbers on the columns correspond from top to bottom to geometric cathode Pt loading $\left(\mathrm{mg} \mathrm{cm}^{-2}\right)$, MEA active area size $\left(\mathrm{cm}^{2}\right)$ and year of publication. Other conditions: $100 \%$ relative humidity, $80{ }^{\circ} \mathrm{C}$. In (a) the stoichiometries are $\mathrm{H}_{2} / \mathrm{O}_{2}$ 2/9.5 and the absolute pressure $150 \mathrm{kPa}_{\text {abs }}$, else stated. "*” marks stoichiometry of $\mathrm{H}_{2} / \mathrm{O}_{2} 1.5 / 10$ and $50 \mathrm{kPa}_{\mathrm{g}}$ inlet, while "**" marks $170 \mathrm{kPa}_{\text {abs }}$ and $\mathrm{H}_{2} / \mathrm{O}_{2}$ flow of 2000/5000 nccm. In (b) the stoichiometries are $\mathrm{H}_{2} /$ Air $1.5 / 2$ and absolute pressure of $150 \mathrm{kPa}_{\text {abs }}$, else stated. "o" marks $170 \mathrm{kPa}_{\mathrm{abs}}$ and "oo" marks $100 \mathrm{kPag}$ inlet. For shape-controlled nanocatalysts, the TEM images by Kongkanand et al. [36], Dionigi et al. [34], Stamenkovic et al. [39,40] and Alia et al. [41] are added on top of the respective columns.

\section{Low Pt loadings and the high current density polarization region}

At high current densities ( $\left.2 \mathrm{~A} / \mathrm{cm}^{2}\right)$ combined with $\mathrm{H}_{2} /$ air feeds (Fig. 2b), voltage losses and power density losses have been known to emerge in the fuel cell polarization behavior. The losses were found to become significant at low geometric Pt mass loadings below $0.1 \mathrm{mg}_{\mathrm{P}} / \mathrm{cm}^{2}$. For some time, this voltage loss remained unaccounted for. Then, several studies in the literature suggested that these voltage losses can be potentially attributed to local oxygen mass transport limitations, which originate from slow oxygen flux at/to the catalytically active interface. Baker et. al and Caulk et al. reported a testing procedure to deconvolute those 
local mass transport voltage losses. [43,44]. The approach is based on limiting current measurements enabling a deconvolution of pressure-dependent and pressure-independent mass transport resistance contributions. Applying this procedure, Owejan et al. reported an increasing resistance in the local mass transport with reduced Pt loadings. The authors also showed a dependence of the local mass transport resistance on both the effective electrochemical Pt surface area and the catalyst nanoparticle distribution, yet they evidence that the local resistance remained independent of the catalytic layer thickness itself [45]. In 2016 finally, Kongkanand et al. referred to the local mass transport resistance as one of the major current issues and challenges for high-power and low Pt-loaded electrodes for PEMFCs [46]. Throughout their simulations they managed to show an inverse scaling of this resistance with the ECSA value, which they converted into a roughness factor and pointed out a significant increase in the local resistance for ECSA values of $40 \mathrm{~m}^{2} / \mathrm{mg}_{\mathrm{Pt}}$ and below. Low ECSA values, that is, low catalytic surface roughness, they argued, would require higher local oxygen flux at the surface of the Pt particles, to match the current and power density demand. Today, the local mass transport issues are referred to as the "local oxygen transport resistance" of a given electrode. This resistance parameter describes the oxygen transport over the last few nanometer, possibly across a thin ionomer film, until the oxygen gas reaches the active catalyst surface.

Recent works gave more detailed insight into local mass transport resistance phenomena within the catalytic electrode layer, as illustrated in Fig. 3. Schuler et al. proposed a modeling and testing procedure varying the gas pressure and molecular weight of the ionomer within a $\mathrm{H}_{2}$-pump setup to differentiate these local oxygen transport phenomena even further [47].

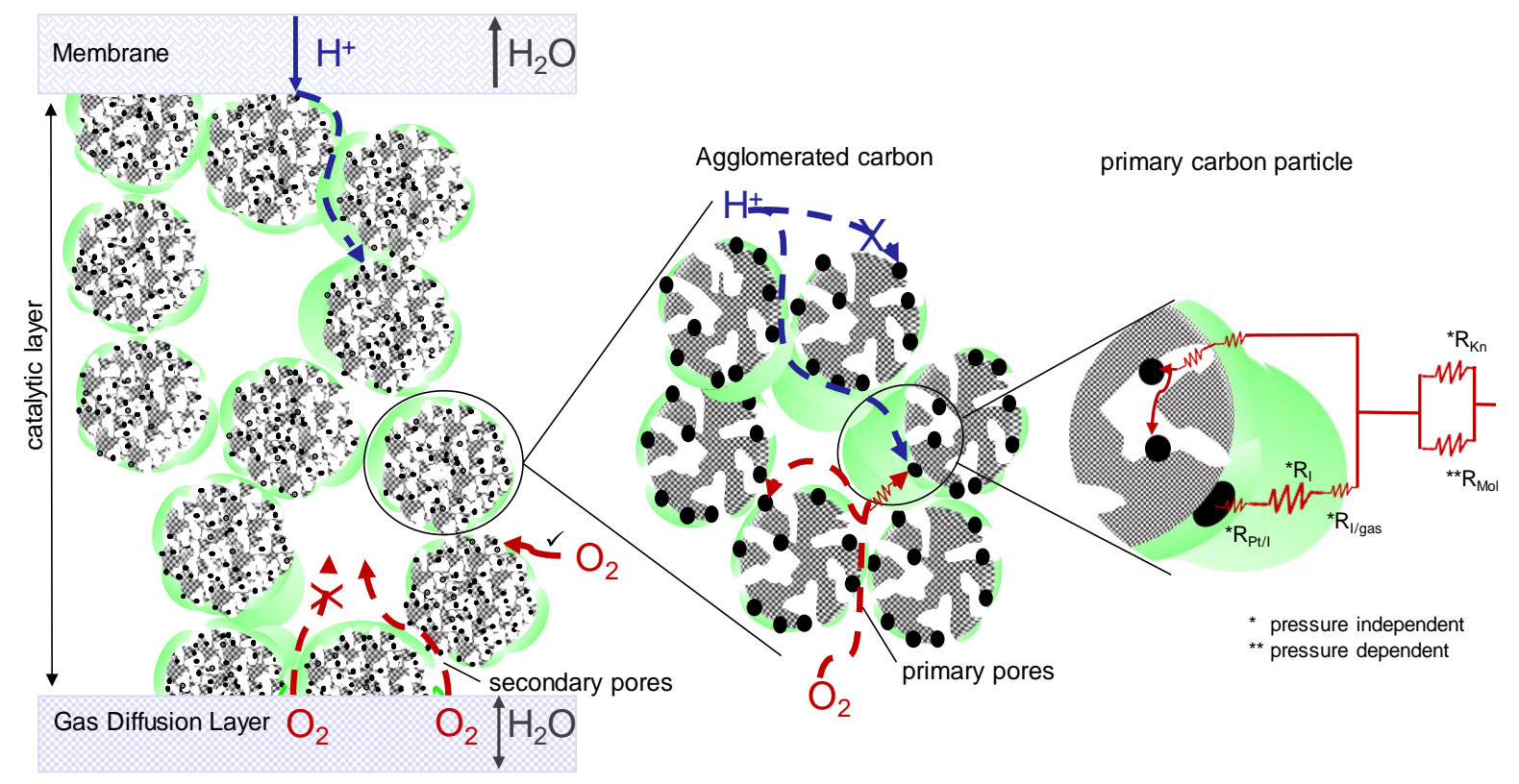

Figure 3. A schematic illustration of the various relevant transport resistances and their length scales inside the catalytic electrode layer of a PEMFC. Left: illustration of the proton transport pathway (blue) and the oxygen pathway (red) through the catalytic layer. Secondary pores form in between primary carbon particles. The check mark denote sufficient gas transport to the active site whereas the cross denotes insufficient one. Middle: Enlarged model of an agglomeration of ionomer-coated primary carbon particle highlighting local gas transport paths as blue and red arrows. The resistance symbol denotes molecular diffusion resistance $\left(\mathrm{R}_{\mathrm{Mol}}\right)$ and Knudsen resistance $\left(\mathrm{R}_{\mathrm{Kn}}\right)$ Right: Spatial deconvolution of the local oxygen transport resistance contributions $\left(\mathrm{R}_{\mathrm{P} / \mathrm{I}}+\mathrm{R}_{\mathrm{I}}+\mathrm{R}_{\mathrm{I} / \mathrm{gas}}\right)$ through secondary pores, across the ionomer layer, and 
in part across primary pores before the reactive gases reach the surface of the active catalyst particles (black dots).

As illustrated in Fig. 3 the catalytic electrode layer is sandwiched between the GDL distributing oxygen over the entire layer and the proton conducting membrane, across which protons, which were generated in the anodic hydrogen oxidation reaction, are conducted into the cathode layer. A closer look at this catalytic layer reveals ionomer-coated agglomerates of microporous carbon particles (primary pores), forming a porous network with secondary pores. Proton transport into these agglomerates and to the catalytic active sites across larger distances is made possible by proton-conducting ionomer distributed across the carbon agglomerates. Depending on their thickness, the ionomer layers generate additional transport resistances for oxygen. Using Cs-doped ionomer and conducting high-angle annular dark field scanning TEM techniques, Lopez-Haro et al. showed an inhomogeneous distribution of this ionomer layer over the entire catalyst layer [48].

Presence of (in particular thick) ionomer clusters can drastically increase the overall oxygen transport resistance within the primary particles and, at the same time, can increase Knudsen resistance $\left(\mathrm{R}_{\mathrm{Kn}}\right)$ by filling/blocking secondary pores partially. The Knudsen transport is pressure independent because it describes oxygen transport controlled by collision with the pore walls. This is why it is dependent on the pore network of the catalyst layer. Absence of ionomer layers on primary particles, on the other hand, will cause severe proton inaccessibility to the active sites. Finally, another pressure independent transport resistance component is restricted to the local oxygen transport near the active site. Schuler et al. accurately extracted the bulk of the overall transport resistance through the ionomer itself $\left(\mathrm{R}_{\mathrm{I}}\right)$ and additional minor contributions, such as the resistance across the ionomer/gas interface $\left(\mathrm{R}_{\mathrm{I} / \mathrm{gas}}\right)$ and the ionomer/Pt interface $\left(\mathrm{R}_{\mathrm{I} / \mathrm{Pt}}\right)$. The sum of these three resistances close to the active site is referred to as local oxygen transport resistance. $\mathrm{R}_{\mathrm{I} / \mathrm{Pt}}$ originates from the Pt-sulfonate interaction [47]. In contrast to the pressure-independent terms, the pressure dependent molecular diffusion resistance $\left(\mathrm{R}_{\mathrm{Mol}}\right)$ is related to the transport properties within the flow field channel, the diffusion media and the microporous layer.

\section{Approaches to improve mass transport in low Pt-loaded electrode layers}

To ensure sufficient access of protons to the catalytic sites of the Pt particles within the pore network of the carbon particles, a direct contact or close proximity between active sites and ionomer is critical. This can be achieved by a partial penetration of the ionomer into these pores, which, in turn, can be realized by pore size tuning or ionomer length modifications. Garsany et al. showed an improvement in high power density for low loaded electrodes using a short side chain, low equivalent weight ionomer binder [49]. A remarkable step forward in the development of tailored catalyst/support couples with improved oxygen accessibility and, thus, reduced local oxygen transport resistance was recently published by Yarlagadda et al. . The authors reported tuning of the pore sizes of high surface area carbons as an effective strategy toward smaller local transport resistances [35]**. As schematically illustrated in Fig. 4a, catalytic sites located in accessible pores offer a compromise between high kinetic, i.e. low current density, performance, on the one hand, and good oxygen transport properties, and consequently excellent high current density performance, on the other. In this scheme, the balanced location of the metal nanoparticles just below the ionomer layers played a very important role. Direct contact with the ionomer would reduce the activity because of the poisoning of active surface sites by the ionomer sulphonate groups, as it occurs for catalyst nanoparticles located on exterior carbon surface $[50,62]$. On the other hand, catalyst nanoparticles deep inside the interior of the primary carbon pores remain inaccessible for the ionomer and, thus, suffer from proton and oxygen mass 
transport losses. The right particle locations depend on the detailed support properties and their synthetic approach. Park et al. and Padgett et al. showed that supports with low porosity, low surface area "solid carbons" stabilize the catalyst nanoparticles preferably on the exterior carbon surface. This is in contrast to high surface area carbon supports that have a large portion of their catalyst nanoparticles in the pore network interior. Harzer et al. demonstrated synthetic methods to control the particle location on high surface area carbons [51]. Controlling the pore size of the support to a range of 4-7 nm enabled clearly reduced mass transport losses for high surface carbons that still maintained high MAs at low currents. The study revealed that increase in the mean pore sizes was correlated with a favorable decrease in the oxygen transport resistance and an increase in dry proton accessibility, supporting the notion of a partial penetration of the ionomer into the pores (Figure $4 \mathrm{~b}$ ). Finding the balanced design of the catalytic layer has remained the key issue for high performing electrodes. Sassin et al. highlighted the importance of the layer porosity and showed how it correlated with the thickness of the catalytic layers to enable sufficient gas and water transport. The thicker the layer got, the more catalyst particles were packed densely causing mass transport issues. On the other hand, thin layers tended to flood [52].

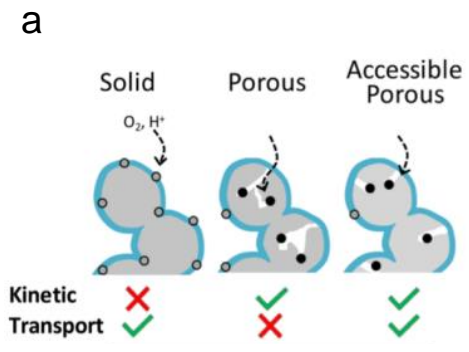

b

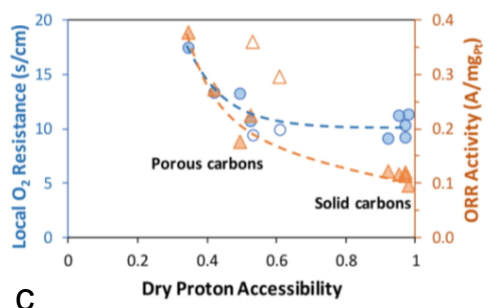

C

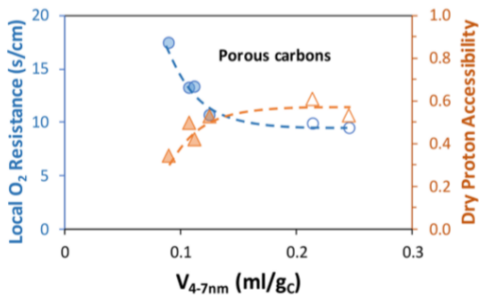

d

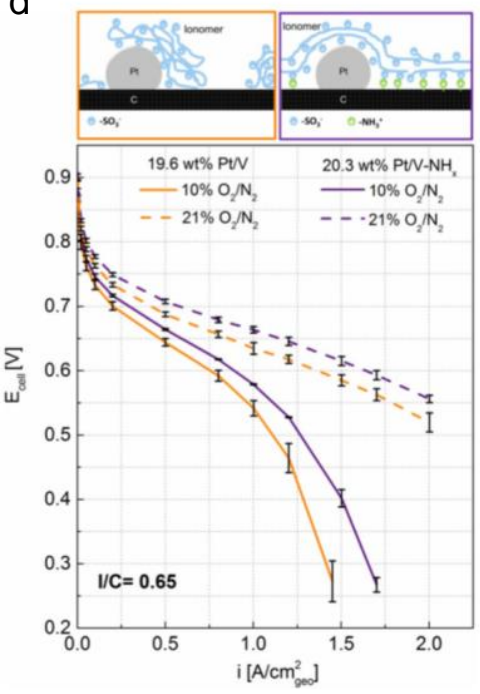

Figure 4. Balancing kinetics and mass transport in electrode layers made of supported metal nanocatalysts. (a) Scheme how three distinct carbon support porosities (solid, porous, and accessible porous) affects the balance between kinetic and transport performance. Green check marks indicate favorable performance, red crosses insufficient performance. Accessible porous carbons where catalytic sites are not blocked by the ionomer, yet are in close proximity below the ionomer layers perform best. (b) Kinetic ORR activity and local $\mathrm{O}_{2}$ resistance as a function of dry proton accessibility of porous and solid carbon-supported Pt nanocatalysts. (c) Proton accessibility and local $\mathrm{O}_{2}$ resistance as a function of pore volume. Whereas open symbols refer to catalysts providing accessible pores. (d) Fuel Cell polarization curves of $\mathrm{NH}_{\mathrm{x}}$-modified and unmodified carbon based catalysts. Insets: illustration how $\mathrm{NH}_{\mathrm{x}}$ modified carbon surfaces stabilize a more uniform ionomer layer on the carbon surface.

Another recent approach to achieve high power performance for low Pt-loaded PEMFC electrodes was presented by Orfanidi et al. modifying the porous carbon support by nitrogen-containing $\left(\mathrm{NH}_{\mathrm{x}}\right)$ functionalities, which were hypothesized to result in an improved ionomer distribution on the carbon surface. The authors reported that more evenly distributed ionomer layers suppress thick ionomer clusters, 
and this decreased the oxygen mass transport resistance [53]*. Indeed, significant improvements of the polarization behavior could be achieved under low oxygen partial pressure operations (Figure 4c). The study highlighted that the ionomer morphology itself is an important performance parameter of the catalytic layer. In another study of the same year, Artyushkova emphasized the orientation and morphology of the ionomer spreading over the entire catalysts' surface in non-noble metal catalysts [54]. Herein, N-moieties influence the ionomer orientation, thus the physical properties such as hydrophobicity that in turn is essential for mass transport and water management.

Finally, another more rarely described catalyst format in an MEA includes the unsupported deployment of advanced Pt catalysts, such as exemplified by the well documented family of perylene whisker-based Ptnanostructured thin films [55]. Unsupported catalysts make for thin layers and are directly exposed to ionomer (so require very little or no ionomer). Therefore, mass transport issues in absence of flooding can be less pronounced. However, they often show low ECSA and suffer of non-uniform coverage of the active area, which constitute critical MEA parameters that need to be optimized for big scale production lines.

\section{Steps towards realization of high power density in low Pt-loaded layers using advanced Pt alloys}

Successful deployment of advanced shape controlled Pt alloys for ORR in low Pt-loaded electrode layers of hydrogen fuel cells appears to require a stepwise approach from RDE to MEA to deconvolute, identify, and mitigate various loss contributions step by step. For example, the FET and the GDE techniques are proposed to serve as intermediate stages of testing to evaluate and screen ORR catalysts at high current densities in a relatively simpler setup than a fuel cell test station. The former allows for investigation of kinetics and mass transport at low and high current densities of very thin catalyst films and very low Pt loadings, similar to RDE, yet under realistic partial pressures of oxygen. The latter offers access for screening of kinetics and mass transport under low and high current densities of thin or thicker catalyst films at normal or low Pt loadings. GDE studies come closest to the actual single MEA tests and, under certain assumptions, may allow the evaluation of oxygen mass transport in analogy to single MEAs. The FET and GDE screening of the ORR activity at high current densities using realistic oxygen partial pressure is therefore the next step after thin-film RDE screening. For the following step, the improvement of performances under air/hydrogen flow, the composition of the catalyst layer is a significant parameter. In particular, the ionomer/carbon ratio is critical for high current densities performance and should be adjusted and optimized with care. To achieve a more uniform distribution of the ionomer, advanced shape-controlled Pt alloy ORR catalysts are best supported on tailored and possible chemically modified carbon supports. The carbon support should be optimized for each of the advanced nanostructured alloy catalysts, because their optimal particle size is different. The modification of the support and the improved ionomer distribution has also the goal to suppress the poisoning of Pt surface sites by the charged functional groups of the ionomer and optimize the oxygen mass transport to the nanostructured catalyst located in accessible carbon pores. MEA-based single fuel cell $\left(5-50 \mathrm{~cm}^{2}\right)$ or in some conditions half-cell GDE can be used for this step. However, we note that the operating conditions of MEA single cell tests, including break-in procedures, should be chosen accurately and accordingly to the results of the preliminary intermediate stages, i.e. FET and GDE, to prevent morphological changes and catalyst degradations. Therefore, a combination of material design at the atomistic scale, layer composition tuning and fuel cell test engineering is necessary for the realization of high power density in low Pt-loaded layers using advanced Pt alloys. 


\section{Concluding remarks and outlook}

To achieve the fuel cell industry-wide objective of low Pt content $\left(<0.05 \mathrm{mg}_{\mathrm{Pt}} / \mathrm{cm}^{2}\right)$ fuel cell electrodes with high Pt utilization efficiency $\left(<0.05 \mathrm{~g}_{\mathrm{Pt}} / \mathrm{kW}\right)$, advanced $\mathrm{Pt}$ (cathode) electrocatalysts with significantly improved ORR catalytic performance inside the electrodes of MEAs continue to remain elusive. The past decade has witnessed remarkable advances in the discovery of highly active dealloyed bimetallic or multimetallic Pt-nanostructured fuel cell cathode catalysts with controlled size, composition, morphology, or shape. Without exceptions, nearly all these novel catalyst concepts exhibited high to extremely high Pt mass-based ORR activities - however, to date, exclusively in a 3-electrode, liquid-electrolyte RDE screening configuration. While projections of the favorable catalytic RDE activities of these advanced dealloyed Pt catalysts to real electrode layers in single fuel cells could imply significant reduction of the Pt content of individual MEAs and fuel cell stacks, not a single advanced catalyst concept has, to date, unfolded its favorable RDE performance in an electrode layer of a bench-scale, let alone application-scale MEA. The molecular chemical or engineering origins of that performance gap has remained elusive. To bridge the device gap between RDE screening and MEA testing, new setups, such as the floating electrode technique or the half-cell gas diffusion electrode technique, have been established. These techniques and devices enable testing of advanced nanocatalysts at low and higher Pt loadings, in thin and thick layer configurations and at low and high current densities, hence, all together under stepwise more realistic operating conditions. This stepwise approach allows for a more accurate estimate and better understanding of the origin of kinetic losses and the various mass transport resistances within the catalytic electrode layers. In addition, these new testing techniques bridging RDE and MEA scales can be combined with new synthetic and engineering approaches for catalyst support materials with tailored pores to minimize mass transport resistances maximizing the high power performance.

We recommended to carry out future characterizations of advanced Pt alloy ORR catalyst concepts in low Pt-loaded electrode layers in a stepwise manner, including RDE, FET, GDE, and finally single cell MEA formats to deconvolute and pinpoint the surface kinetic and transport-related origins of the serious power density and efficiency gaps between RDE and MEA. After all, optimizing a catalytic reactive layer is an extremely complex balance act of support characteristics, properties of the active metallic catalyst phase itself, as well as the nature of the ionomer environment.

In addition to a deconvolution of kinetics and mass transport at low and high current densities in a hierarchy of testing techniques, fundamental insights into the morphological and compositional changes of support and catalyst in realistic electrode layers, using operando fuel cell analysis techniques, have gained increased attention lately. Insights into performance losses may include clues as to the role of carbon support motion, catalyst motion, or other metal or support degradation mechanisms. Real-time observation and visualization can shed light on the nanoscale processes relevant for an improvement of the catalyst/support/ionomer complex. Some groups have reported their related researches about in situ TEM [32,33], in situ X-ray absorption spectroscopy [56,57] and in situ X-ray scattering [34,58]. However, more studies of advanced ORR catalysts in MEAs under operating conditions are needed to reach the performance targets.

\section{Acknowledgements}

The collaborative GAIA EU research and development project has received funding from the Fuel Cells and Hydrogen 2 Joint Undertaking under grant agreement No 826097. This Joint Undertaking receives 
support from the European Union's Horizon 2020 research and innovation programme, Hydrogen Europe and Hydrogen Europe Research. 


\section{References and recommended reading}

Papers of particular interest, published within the period of review, have been highlighted as:

* of special interest

$* *$ of outstanding interest

1. Cui C, Gan L, Heggen M, Rudi S, Strasser P: Compositional segregation in shaped Pt alloy nanoparticles and their structural behaviour during electrocatalysis. Nature Materials 2013, 12:765771.https://doi.org/10.1038/nmat3668

2. Huang X, Zhao Z, Cao L, Chen Y, Zhu E, Lin Z, Li M, Yan A, Zettl A, Wang YM, et al.: Highperformance transition metal-doped $\mathrm{Pt}_{3} \mathrm{Ni}$ octahedra for oxygen reduction reaction. Science 2015, 348:1230-1234.https://doi.org/10.1126/science.aaa8765

3. Gan L, Rudi S, Cui C, Heggen M, Strasser P: Size-controlled synthesis of sub-10 nm PtNi alloy nanoparticles and their unusual volcano-shaped size effect on ORR electrocatalysis. Small 2016, 12:3189-3196.https://doi.org/10.1002/smll.201600027

4. Schmidt TJ, Gasteiger HA, Stäb GD, Urban PM, Kolb DM, and Behm RJ: Characterization of high - surface - area electrocatalysts using a rotating disk electrode configuration. J. Electrochem. Soc. 1998, 145:2354.https://doi.org/10.1149/1.1838642

5. Paulus UA, Schmidt TJ, Gasteiger HA, Behm RJ: Oxygen reduction on a high-surface area Pt:Vulcan carboncatalyst: a thin-film rotating ring-disk electrode study. Journal of Electroanalytical Chemistry 4 2001, 495:34 - 145.https://doi.org/10.1016/S0022-0728(00)00407-1

6. * Martens S, Asen L, Ercolano G, Dionigi F, Zalitis C, Hawkins A, Bonastre AM, Seidl L, Knoll AC, Sharman J, et al.: A comparison of rotating disc electrode, floating electrode technique and membrane electrode assembly measurements for catalyst testing. Journal of Power Sources 2018, 392:274-284.https://doi.org/10.1016/j.jpowsour.2018.04.084

By using a carbon supported platinum benchmark catalyst, the authors developed a protocol to conduct reproducible RDE measurements. In addition, data obtained from MEA and FET testing showed similar trends comparable to the RDE measurement region. This paper rationalized the preliminary screening function of RDE and that the catalysts' performance could be supplemented with further cell techniques.

7. Pedersen CM, Escudero-Escribano M, Velazquez-Palenzuela A, Christensen LH, Chorkendorff I, Stephens IEL: Benchmarking Pt-based electrocatalysts for low temperature fuel cell reactions with the rotating disk electrode: oxygen reduction and hydrogen oxidation in the presence of $\mathrm{CO}$ (review article). Electrochimica Acta 2015, 179:647-657.https://doi.org/10.1016/j.electacta.2015.03.176 
8. Luo M, Guo S: Multimetallic electrocatalyst stabilized by atomic ordering. Joule 2019, 3:910.https://doi.org/10.1016/j.joule.2018.12.020

9. Zalitis CM, Kramer D, Kucernak AR: Electrocatalytic performance of fuel cell reactions at low catalyst loading and high mass transport. Physical Chemistry Chemical Physics 2013, 15:43294340.https://doi.org/10.1039/c3cp44431g

10. Pinaud BA, Bonakdarpour A, Daniel L, Sharman J, Wilkinson DP: Key considerations for high current fuel cell catalyst testing in an electrochemical half-cell. Journal of the Electrochemical Society 2017, 164:F321-F327.https://doi.org/10.1149/2.0891704jes

11. Inaba M, Jensen AW, Sievers GW, Escudero-Escribano M, Zana A, Arenz M: Benchmarking high surface area electrocatalysts in a gas diffusion electrode: measurement of oxygen reduction activities under realistic conditions. Energy \& Environmental Science 2018, 11:988994.https://doi.org/10.1039/c8ee00019k

12. Kim C, Dionigi F, Beermann V, Wang X, Möller T, Strasser P: Alloy nanocatalysts for the electrochemical oxygen reduction (ORR) and the direct electrochemical carbon dioxide reduction reaction (CO2RR). Advanced Materials 0:1805617.https://doi.org/10.1002/adma.201805617

13. Guy D, Maciej S, and Kirsty-Jo W: Handbook of Electrochemistry. Edited by Zoski CG: Elsevier Science; 2007.

14. Cooper K, Ramani V, Fenton J, Kunz H: Experimental methods and data analyses for polymer electrolyte fuel cells: Scribner Associates; 2005.

15. Strasser P, Koh S, Anniyev T, Greeley J, More K, Yu C, Liu Z, Kaya S, Nordlund D, Ogasawara $\mathrm{H}$, et al.: Lattice-strain control of the activity in dealloyed core-shell fuel cell catalysts. Nat Chem 2010, 2:454-460.https://doi.org/10.1038/nchem.623

16. Xia BY, Wu HB, Li N, Yan Y, Lou XW, Wang X: One-pot synthesis of Pt-Co alloy nanowire assemblies with tunable composition and enhanced electrocatalytic properties. Angew Chem Int Ed Engl 2015, 54:3797-3801.https://doi.org/10.1002/anie.201411544

17. Gan L, Cui CH, Heggen M, Dionigi F, Rudi S, Strasser P: Element-specific anisotropic growth of shaped platinum alloy nanocrystals. Science 2014, 346:1502-

1506.https://doi.org/10.1126/science. 1261212

18. Jia Q, Zhao Z, Cao L, Li J, Ghoshal S, Davies V, Stavitski E, Attenkofer K, Liu Z, Li M, et al.: Roles of Mo surface dopants in enhancing the ORR performance of octahedral PtNi nanoparticles. Nano Lett 2018, 18:798-804.https://doi.org/10.1021/acs.nanolett.7b04007 
19. Beermann V, Gocyla M, Willinger E, Rudi S, Heggen M, Dunin-Borkowski RE, Willinger MG, Strasser P: Rh-doped Pt-Ni octahedral nanoparticles: understanding the correlation between elemental distribution, oxygen reduction reaction, and shape stability. Nano Lett 2016, 16:17191725.https://doi.org/10.1021/acs.nanolett.5b04636

20. Lim J, Shin H, Kim M, Lee H, Lee KS, Kwon Y, Song D, Oh S, Kim H, Cho E: Ga-doped Pt-Ni octahedral nanoparticles as a highly active and durable electrocatalyst for oxygen reduction reaction. Nano Lett 2018, 18:2450-2458.https://doi.org/10.1021/acs.nanolett.8b00028

21. Calle-Vallejo F, Tymoczko J, Colic V, Vu QH, Pohl MD, Morgenstern K, Loffreda D, Sautet P, Schuhmann W, Bandarenka AS: Finding optimal surface sites on heterogeneous catalysts by counting nearest neighbors. Science 2015, 350:185-189.https://doi.org/10.1126/science.aab3501

22. Wang L, Zeng Z, Gao W, Maxson T, Raciti D, Giroux M, Pan X, Wang C, Greeley J: Tunable intrinsic strain in two-dimensional transition metal electrocatalysts. Science 2019, 363:870874.https://dio.org/10.1126/science.aat8051

23. Li G, Zhao Z, Cheng T, Fortunelli A, Chen C, Yu R, Zhang Q, Gu L, Merinov B, Lin Z, et al.: Ultrafine jagged platinum nanowires enable ultrahigh mass activity for the oxygen reduction reaction. Science 2016, 354:1414-1419.https://doi.org/10.1126/science.aaf9050

24. Escudero-Escribano M, Malacrida P, Hansen MH, Vej-Hansen UG, Velazquez-Palenzuela A, Tripkovic V, Schiotz J, Rossmeisl J, Stephens IEL, Chorkendorff I: Tuning the activity of Pt alloy electrocatalysts by means of the lanthanide contraction. Science 2016, 352:7376.https://doi.org/10.1126/science.aad8892

25. Schwammlein JN, Harzer GS, Pfandner P, Blankenship A, El-Sayed HA, Gasteiger HA: Activity and stability of carbon supported $\mathrm{Pt}_{\mathrm{x}} \mathrm{Y}$ alloys for the ORR determined by RDE and single-cell PEMFC measurements. Journal of the Electrochemical Society 2018, 165:J3173J3185.https://doi.org/10.1149/2.0221815jes

26. Lindahl N, Eriksson B, Grönbeck H, Lindström RW, Lindbergh G, Lagergren C, and Wickman B: Fuel cell measurements with cathode catalysts of sputtered $\mathbf{P t}_{3} \mathbf{Y}$ thin films. ChemSusChem 2018, 11:1-9.https://doi.org/10.1002/cssc.201800023

27. Ma SY, Li HH, Hu BC, Cheng X, Fu QQ, Yu SH: Synthesis of low Pt-based quaternary PtPdRuTe nanotubes with optimized incorporation of Pd for enhanced electrocatalytic activity. $J$ Am Chem Soc 2017, 139:5890-5895.https://doi.org/10.1021/jacs.7b01482

28. Lim B, Jiang M, Tao J, Camargo PHC, Zhu Y, Xia Y: Shape-controlled synthesis of Pd nanocrystals in aqueous solutions. Advanced Functional Materials 2009, 19:189200.https://doi.org/10.1002/adfm.200801439 
29. Xia Y, Xiong Y, Lim B, Skrabalak SE: Shape-controlled synthesis of metal nanocrystals: simple chemistry meets complex physics? Angew Chem Int Ed Engl 2009, 48:60-

103.https://doi.org/10.1002/anie.200802248

30. Mauger SA, Neyerlin KC, Alia SM, Ngo C, Babu SK, Hurst KE, Pylypenko S, Litster S, and Pivovar BS: Fuel cell performance implications of membrane electrode assembly fabrication with platinum-nickel nanowire catalysts. Journal of The Electrochemical Society 2018, 165:F238F245.https://doi.org/10.1149/2.1061803jes]

31. Zhu G-Z, Prabhudev S, Yang J, Gabardo CM, Botton GA, Soleymani L: In situ liquid cell TEM study of morphological evolution and degradation of $\mathrm{Pt}-\mathrm{Fe}$ nanocatalysts during potential cycling. The Journal of Physical Chemistry C 2014, 118:22111-22119.https://doi.org/10.1021/jp506857b

32. Hodnik N, Dehm G, Mayrhofer KJ: Importance and challenges of electrochemical in situ liquid cell electron microscopy for energy conversion research. Acc Chem Res 2016, 49:20152022.https://doi.org/10.1021/acs.accounts.6b00330

33. Beermann V, Holtz ME, Padgett E, Ferreira de Araujo J, Muller D, Strasser P: Real-time imaging of activation and degradation of carbon supported octahedral $\mathrm{Pt}-\mathrm{Ni}$ alloy fuel cell catalysts at the nanoscale using in situ electrochemical liquid cell STEM. Energy \& Environmental Science 2019.https://doi.org/10.1039/C9EE01185D

34. Dionigi F, Weber CC, Primbs M, Gocyla M, Bonastre AM, Spöri C, Schmies H, Hornberger E, Kühl S, Drnec J, et al.: submitted. 2019,

35. ** Yarlagadda V, Carpenter MK, Moylan TE, Kukreja RS, Koestner R, Gu WB, Thompson L, Kongkanand A: Boosting fuel cell performance with accessible carbon mesopores. Acs Energy Letters 2018, 3:618-621.https://doi.org/10.1021/acsenergylett.8b00186

This work addresses the importance of the supports' pore structure towards transport phenomena within the catalytic layer and reveals unprecedented high power densities for PtCo catalysts.

36. Kongkanand A, Mathias MF: The priority and challenge of high-power performance of lowplatinum proton-exchange membrane fuel cells. Journal of Physical Chemistry Letters 2016, 7:11271137.https://doi.org/10.1021/acs.jpclett.6b00216

37. Han BH, Carlton CE, Kongkanand A, Kukreja RS, Theobald BR, Gan L, O'Malley R, Strasser P, Wagner FT, Shao-Horn Y: Record activity and stability of dealloyed bimetallic catalysts for proton exchange membrane fuel cells. Energy \& Environmental Science 2015, 8:258-

266.https://doi.org/10.1039/c4ee02144d

38. * Garrick TR, Moylan TE, Carpenter MK, Kongkanand A: Electrochemically active surface area measurement of aged Pt alloy catalysts in PEM fuel cells by CO stripping. Journal of the Electrochemical Society 2017, 164:F55-F59.https://doi.org/10.1149/2.0381702jes 
This work reported ECSA and MA of high activity alloy catalysts in MEA by CO stripping and hydrogen adsorption/desorption (HAD).

39. Stamenkovic V, Markovic NM: Nanosegregated cathode catalysts with ultra-low platinum loading. In 2015 DOE Hydrogen and Fuel Cells Program Review. Edited by Energy USDo; 2015.

40. Stamenkovic V, Markovic NM: Tailored high performance low-PGM alloy cathode catalysts. In 2018 DOE Hydrogen and Fuel Cells Program Review. Edited by Energy USDo; 2018.

41. Alia S, Pivovar BS: Extended surface electrocatalyst development. In DOE Hydrogen and Fuel Cells Program 2018 Annual Merit Review and Peer Evaluation Meeting. Edited by Energy USDo; 2018.

42. Peng X, Zhao S, Omasta TJ, Roller JM, Mustain WE: Activity and durability of Pt-Ni nanocage electocatalysts in proton exchange membrane fuel cells. Applied Catalysis B-Environmental 2017, 203:927-935.https://doi.org/10.1016/j.apcatb.2016.10.081

43. Baker DR, Caulk DA, Neyerlin KC, Murphy MW: Measurement of oxygen transport resistance in PEM fuel cells by limiting current methods. Journal of The Electrochemical Society 2009, 156:B991.https://doi.org/10.1149/1.3152226

44. Caulk DA, Baker DR: Heat and water transport in hydrophobic diffusion media of PEM fuel cells. Journal of The Electrochemical Society 2010, 157:B1237.https://doi.org/10.1149/1.3454721

45. Owejan JP, Owejan JE, and Gu W: Impact of platinum loading and catalyst layer structure on PEMFC performance. Journal of The Electrochemical Society 2013, 160:F824-

F833.https://doi.org/10.1149/2.072308jes]

46. Kongkanand A, Subramanian NP, Yu Y, Liu Z, Igarashi H, Muller DA: Achieving high-power PEM fuel cell performance with an ultralow-Pt-content core-shell catalyst. ACS Catalysis 2016, 6:1578-1583.https://doi.org/10.1021/acscatal.5b02819

47. Schuler T, Chowdhury A, Freiberg AT, Sneed B, Spingler FB, Tucker MC, More KL, Radke CJ, and Weber AZ: Fuel-cell catalyst-layer resistance via hydrogen limiting-current measurements. Journal of The Electrochemical Society 2019, 166:F3020-F3031.https://doi.org/10.1149/2.0031907jes]

48. Lopez-Haro M, Guetaz L, Printemps T, Morin A, Escribano S, Jouneau PH, Bayle-Guillemaud P, Chandezon F, Gebel G: Three-dimensional analysis of Nafion layers in fuel cell electrodes. Nat Commun 2014, 5:5229.https://doi.org/10.1038/ncomms6229 
49. Garsany Y, Atkinson RW, Gould BD, Swider-Lyons KE: High power, low-Pt membrane electrode assemblies for proton exchange membrane fuel cells. Journal of Power Sources 2018, 408:38-45.https://doi.org/10.1016/j.jpowsour.2018.10.073

50. Ono Y, Ohma A, Shinohara K, and Fushinobu K: Influence of equivalent weight of ionomer on local oxygen transport resistance in cathode catalyst layers. Journal of The Electrochemical Society 2013, 160:F779-F787.https://doi.org/10.1149/2.040308jes]

51. Harzer GS, Orfanidi A, El-Sayed H, Madkikar P, and Gasteiger HA: Tailoring catalyst morphology towards high performance for low Pt loaded PEMFC cathodes. Journal of The Electrochemical Society 2018, 165:F770-F779.https://doi.org/10.1149/2.0311810jes]

52. Sassin MB, Garsany Y, Atkinson RW, Hjelm RME, Swider-Lyons KE: Understanding the interplay between cathode catalyst layer porosity and thickness on transport limitations en route to high-performance PEMFCs. International Journal of Hydrogen Energy 2019, 44:1694416955.https://doi.org/10.1016/j.ijhydene.2019.04.194

53. * Orfanidi A, Madkikar P, El-Sayed HA, Harzer GS, Kratky T, and Gasteiger HA: The key to high performance low Pt loaded electrodes. Journal of The Electrochemical Society 2017, 164:F418F426.https://doi.org/10.1149/2.1621704jes]

This paper presents a synthetic approach to realize low Pt loaded electrodes by conducting a carbon modification step what leads to reduced voltage losses in high current density region.

54. Artyushkova K, Workman MJ, Matanovic I, Dzara MJ, Ngo C, Pylypenko S, Serov A, Atanassov $\mathrm{P}$ : Role of surface chemistry on catalyst/ionomer interactions for transition metal-nitrogen-carbon electrocatalysts. ACS Applied Energy Materials 2017, 1:68-77.https://doi.org/10.1021/acsaem.7b00002

55. Debe MK, Steinbach AJ, Vernstrom GD, Hendricks SM, Kurkowski MJ, Atanasoski RT, Kadera P, Stevens DA, Sanderson RJ, Marvel E, et al.: Achieving high-power PEM fuel cell performance with an ultralow-Pt-content core-shell catalyst. Journal of The Electrochemical Society 2011, 158:B910B918 https://doi.org/10.1149/1.3595748]

56. Kaito T, Tanaka H, Mitsumoto H, Sugawara S, Shinohara K, Ariga H, Uehara H, Takakusagi S, Asakura K: In situ X-ray absorption fine structure analysis of PtCo, PtCu, and PtNi alloy electrocatalysts: the correlation of enhanced oxygen reduction reaction activity and structure. The Journal of Physical Chemistry C 2016, 120:11519-11527.https://doi.org/10.1021/acs.jpcc.6b01736

57. Becknell N, Kang YJ, Chen C, Resasco J, Kornienko N, Guo JH, Markovic NM, Somorjai GA, Stamenkovic VR, Yang PD: Atomic structure of $\mathbf{P t}_{3} \mathbf{N i}$ nanoframe electrocatalysts by in situ X-ray absorption spectroscopy. Journal of the American Chemical Society 2015, 137:1581715824.https://doi.org/10.1021/jacs.5b09639 
58. Schmies H, Bergmann A, Drnec J, Wang G, Teschner D, Kühl S, Sandbeck DJS, Cherevko S, Gocyla M, Shviro M, et al.: Unravelling degradation pathways of oxide-supported Pt fuel cell nanocatalysts under in situ operating conditions. Advanced Energy Materials 2018, 8:1701663.https://doi.org/10.1002/aenm.201701663

59. Treimer S, Tang A, Johnson DC: A consideration of the application of Koutecký Levich plots in the diagnoses of charge transfer mechanisms at rotated disk electrodes. Electroanalysis 2002, 14:165-171, https://doi.org/10.1002/1521-4109(200202)14:3.

60. Masa J, Batchelor-McAuley C, Schuhmann W, Compton RG: Koutecky-Levich analysis applied to nanoparticle modified rotating disk electrodes: electrocatalysis or misinterpretation. Nano Res 2013, 7:71-78, https://doi.org/10.1007/s12274-013-0372-0.

61. Zhou R, Zheng Y, Jaroniec M, Qiao SZ: Determination of the electron transfer number for the oxygen reduction reaction: from theory to experiment. ACS Catal 2016, 6:4720-4728, https://doi.org/10.1021/acscatal.6b01581.

62. Ott S, Orfanidi A, Schmies H, Anke B, Nong HN, Hübner J, Gernert U, Gliech M, Lerch M, Strasser P: Ionomer distribution control in porous carbon-supported catalyst layers for highpower and low Pt-loaded proton exchange membrane fuel cells. Nat Mater 2019, https://doi.org/10.1038/s41563-019-0487-0. 